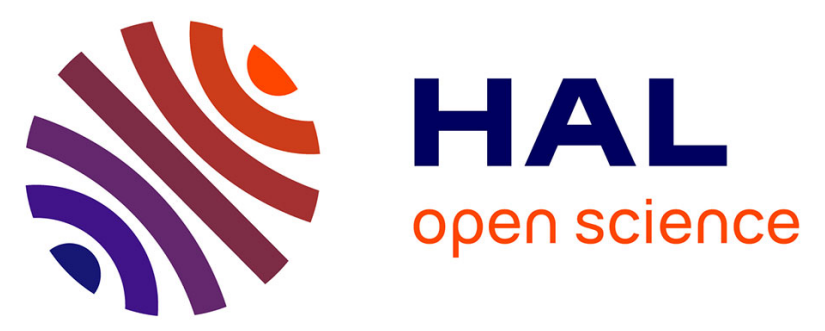

\title{
Effects of silver catalyst concentration in metal assisted chemical etching of silicon
}

\author{
Ragavendran Venkatesan, Muthu Kumar Arivalagan, Vishnukanthan \\ Venkatachalapathy, Joshua Pearce, Jeyanthinath Mayandi
}

\section{To cite this version:}

Ragavendran Venkatesan, Muthu Kumar Arivalagan, Vishnukanthan Venkatachalapathy, Joshua Pearce, Jeyanthinath Mayandi. Effects of silver catalyst concentration in metal assisted chemical etching of silicon. Materials Letters, 2018, 221, pp.206-210. 10.1016/j.matlet.2018.03.053 . hal02111384

\section{HAL Id: hal-02111384 \\ https://hal.science/hal-02111384}

Submitted on 26 Apr 2019

HAL is a multi-disciplinary open access archive for the deposit and dissemination of scientific research documents, whether they are published or not. The documents may come from teaching and research institutions in France or abroad, or from public or private research centers.
L'archive ouverte pluridisciplinaire HAL, est destinée au dépôt et à la diffusion de documents scientifiques de niveau recherche, publiés ou non, émanant des établissements d'enseignement et de recherche français ou étrangers, des laboratoires publics ou privés. 


\title{
Effects of silver catalyst concentration in metal assisted chemical etching of silicon
}

Ragavendran Venkatesan ${ }^{1}$, Muthu Kumar Arivalagan ${ }^{1}$, Vishnukanthan Venkatachalapahy,2, Joshua M. Pearce ${ }^{4,5,6}$, Jeyanthinath Mayandi ${ }^{1, *}$

1,* Department of Materials Science, School of Chemistry, Madurai Kamaraj University, Madurai-625 021, India. E-mail: jeyanthinath@yahoo.co.in

${ }^{2}$ Department of Physics, Centre for Materials Science and Nanotechnology, University of Oslo, PO Box 1048 Blindern, N-0316 Oslo, Norway

${ }^{3}$ Department of Materials Science, National Research Nuclear University “MEPhI”, 31 Kashirskoe sh, Moscow, Russian Federation

${ }^{4}$ Department of Electronics and Nano engineering, School of Electrical Engineering, Aalto University, Espoo, Finland

${ }^{5}$ Department of Materials Science and Engineering, Michigan Technological University, Houghton, MI 49931, USA

${ }^{6}$ Department of Electrical and Computer Engineering, Michigan Technological University, Houghton, MI 49931, USA

\begin{abstract}
:
A systematic investigation is performed to determine the effects of the concentration of silver on metal assisted chemical etching (MaCE) on nanostructure formation mechanisms on silicon as well as their resultant optical properties. Silver nitrate concentrations of $0.008 \mathrm{M}$, $0.004 \mathrm{M}, 0.003 \mathrm{M}$ and $0.002 \mathrm{M}$ with hydrogen fluoride were used for the preparation of p-type silicon nanostructures. Experimentally it is observed that when the catalysis molarity concentration is decreased in the etching processes, it resulted in macro, micro and nanostructures from 140 to $60 \mathrm{~nm}$, respectively over the concentrations investigated. A detailed investigation of the optical and structure provided insight into the physics of their formation. In addition, the results show the silicon nanostructures formed black silicon where in the visible region of the spectrum the reflectance dropped by an order of magnitude. The results indicate MaCE is a promising approach to the manufacturing of antireflection coatings on black silicon-based solar photovoltaic cells. MaCE is a simple and scalable approach to enhance the optical absorption of silicon and improve the overall efficiency of the solar cell without adding significantly to the complexity, capital expenditure or cost of production.
\end{abstract}

Keywords: Metal assisted chemical etching, silver catalyst, silicon nanostructures, antireflection, photovoltaic

\section{Introduction:}

Silicon nanostructures have been under intense investigation for the past two decades [1] because of their potential applications in solar photovoltaics [2], thermoelectrics [3], micromachining [4], energy storage [5], field emission [6], photodetectors [7], optical modulators [8] and in sensing devices [9]. Amongst various methods used for fabrication of silicon nanostructures [10, 11], MaCE is one of the simplest and least expensive [12]. With MaCE previously deposited noble metal layers or particles act as catalysts for oxidant reduction in the etching solution and provides the required hole-current for silicon dissolution [13]. Preferred metal catalysts are silver, gold, platinum and palladium [14, 15] deposited by various techniques such as sputtering [16], evaporation [17], electrochemical [18] or electroless displacement [19]. The metal is deposited as spatially separated nano-clusters or as a continuous metal layer depending on the deposition method. After metal deposition, a solution containing hydrofluoric acid and an oxidizing agent such as hydrogen peroxide or 
nitric acid etches the silicon [13]. Although a theoretical model of etching exists for both continuous [20] and locally distributed [10] metal catalysts on silicon, the influence of the metal concentration on the etching process has not been well investigated.

To begin to fill in this scientific knowledge gap, this study illustrates the process flow of nanostructure formation by varying the catalysis concentration on the silicon substrate through MaCE. The resultant black silicon materials are characterized both microstructurally and optically to provide further insight into the physics of the nano silicon formation, as well as evaluate them for applications in solar photovoltaic devices.

\section{Method:}

Double sided polished p-type electronic grade $525 \mu \mathrm{m}$ silicon wafers (100) were used for the etching process. The silicon wafers where subjected to Radio Corporation of America (RCA) cleaning and were cleaved to produce $1 \mathrm{~cm} \times 1 \mathrm{~cm}$ samples. Then a protective oxide layer was formed using a piranha solution of sulphuric acid and hydrogen peroxide $\left(\mathrm{H}_{2} \mathrm{SO}_{4}: \mathrm{H}_{2} \mathrm{O}_{2}\right)$ in a volume ratio of $3: 1$ at $0^{\circ} \mathrm{C}$ for 10 minutes. Before the etching process the oxide layer was removed by dipping the sample in a water and hydrogen fluoride $\left(\mathrm{H}_{2} \mathrm{O}: \mathrm{HF}\right)$ solution with the volume ratio of 10:1 for 3 minutes at room temperature. Then the silver nanoparticles (Ag NPs) were coated on the freshly cleaned Si wafers by immersing in a $3.6 \mathrm{ml}$ bath of HF with $25 \mathrm{ml}$ of silver nitrate $\left(\mathrm{AgNO}_{3}\right)$ aqueous solution for one minute. The excess $\mathrm{Ag}^{+}$ions present in the surface were washed with distilled water, then samples were immersed in etching solution comprising $3.6 \mathrm{ml}$ of $\mathrm{HF}$ in $20 \mathrm{ml}$ of $\mathrm{H}_{2} \mathrm{O}$ and $0.6 \mathrm{ml}$ of $\mathrm{H}_{2} \mathrm{O}_{2}$ for 45 minutes. The different concentrations with molar ratios $0.008 \mathrm{M}, 0.004 \mathrm{M}, 0.003 \mathrm{M}$ and $0.002 \mathrm{M}$ of $\mathrm{AgNO}_{3}$ were used for the preparation of silicon nanostructures with a constant etching time and are labelled as (a, b, c, d) respectively. The residual Ag NPs on the sample surface and in the pores of the Si were removed by immersing the samples in diluted nitric acid $\left(\mathrm{HNO}_{3}\right)$ for 60 minutes. Finally, the prepared samples were washed with distilled water and dried in nitrogen $\left(\mathrm{N}_{2}\right)$.

The resultant samples were characterized using scanning electron microscopy (SEM) to analyse the morphology of the silicon nanostructures. The optical properties of the silicon nanostructures were measured in a range from $300 \mathrm{~nm}$ to $800 \mathrm{~nm}$ using a JASCO (V 650) UV-Vis spectrometer. The diffuse reflectance spectroscopy (DRS) method was used to obtain the surface reflectance.

\section{Results and Discussion:}

\subsection{SEM:}

Fig. 1 displays SEM micrographs of the silver nanoparticles on the silicon surface with various concentrations. The white spots on the SEM image are Ag nanoparticle randomly distributed on the silicon surface. The respective histogram is shown as the inset in Fig. 1. As can be seen by Fig. 1 as the concentration decreases the size of the Ag NPs decreases.

Fig. 2 shows the top-view SEM images at $7 \mathrm{kX}$ and $20 \mathrm{kX}$ of the as-prepared silicon nanostructured arrays with different concentrations of $\mathrm{AgNO}_{3}$. Comparing the top views of silicon nanowires, the surface density decreased with increase of $\mathrm{AgNO}_{3}$ concentration as would be expected. Thus, the size of the voids in the sample (a) is larger than the other samples, because of the higher concentration of Ag. 
For a clearer understanding of the morphology of the Si nanostructures, Fig. 3 shows a typical cross-sectional SEM image of a sample (b) at two resolutions $7 \mathrm{kX}$ and $20 \mathrm{kX}$. One can see that silicon nanostructures look like quasi-ordered nano-grass with preferential orientation along the [100] crystallographic direction. This indicates that the MACE of $c$-Si in HF-solution is strongly crystallographic oriented, which is in agreement with results of past studies [21, 22]. While the thickness (diameter size) of silicon nanostructures is variable (about 60 to $140 \mathrm{~nm}$ ) in the form of an array, for each individual silicon nanostructure the diameter does not vary significantly along the length. Since the concentrations of HF and $\mathrm{H}_{2} \mathrm{O}_{2}$ are constant in this experiment, the etching rate will not change with $\mathrm{AgNO}_{3}$ concentration. The amount of Ag nanoparticles on the silicon surface influence the surface density of the silicon nanowire arrays rather than the length. The length of silicon nanostructures is controlled by duration of the etching catalysed by Ag nanoparticles. In this work, the duration of etching is kept constant as 45 minutes, thus the length of the silicon nanostructures is constant at around $9 \mu \mathrm{m}$. The silver contamination in the silicon nanostructures was easily removed by the samples in $\mathrm{HNO}_{3}$ solution.

Less intuitively, the linear variation of the normalized etch rate of silicon nanostructures depends on the concentration of Ag NPs. This is a result of the process of HF diffusion toward the Ag NP/Si interface to dissolve oxidized Si surface atoms after hole injection from the Ag NPs. For the higher concentrations the time needed for the HF to diffuse the oxidized Si is longer. The etch rate is affected by the "free" area between Ag NPs, in the sense that the etching rate decreases when Ag NPs get closer. In this work, it is assumed that the normalization allows to roughly take into account the influence of the distance between Ag NPs on etch rates, with the exception of the sample with the lowest coverage and smallest NP size. This is because the increase of the etching depth resulted in a lower probability for HF to access the interface.

In addition, the aggregation of the Ag NPs also affects the diffusion of the etching solution. A critical parameter in the formation of nanostructures by MaCE is the attraction between the metal catalyst and the substrate material [21]. Throughout the reaction, the Ag nanoparticles maintains an intimate contact with the silicon, sinking with the silicon as it is etched. 


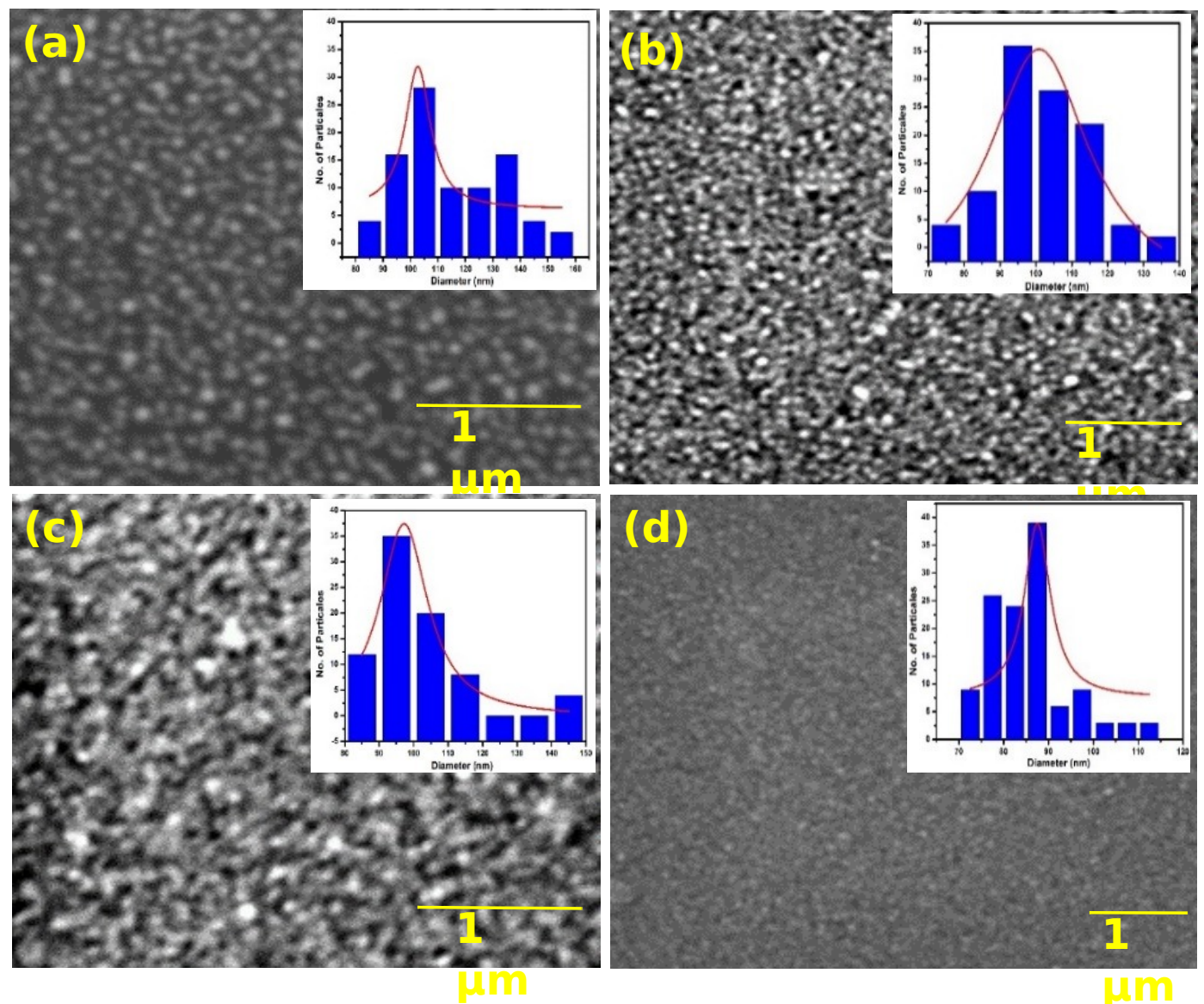

Fig. 1: SEM images of AgNPs on silicon for various molar ratios of $\mathrm{AgNO}_{3}$ (a)

$0.008 \mathrm{M}$, (b) $0.004 \mathrm{M}$, (c ) $0.003 \mathrm{M} \&$ (d) $0.002 \mathrm{M}$. The distribution of the particle size is shown in the inset of each image and the average particle size for (a) $110 \pm 20 \mathrm{~nm}$, (b) $100 \pm 10 \mathrm{~nm}$, (c) $90 \pm 20 \mathrm{~nm}$, (d) $80 \pm 15 \mathrm{~nm}$. For all $\mathrm{AgNO}_{3}$ concentrations metal clusters show logarithmicnormal distributions.

Fig. 2 shows the top-view SEM images at $7 \mathrm{kX}$ and $20 \mathrm{kX}$ of the as-prepared silicon nanostructured arrays with different concentrations of $\mathrm{AgNO}_{3}$. Comparing the top views of silicon nanowires, the surface density decreased with increase of $\mathrm{AgNO}_{3}$ concentration. The size of the voids in the sample (a) is larger than the other samples, because of the higher concentration of Ag. 

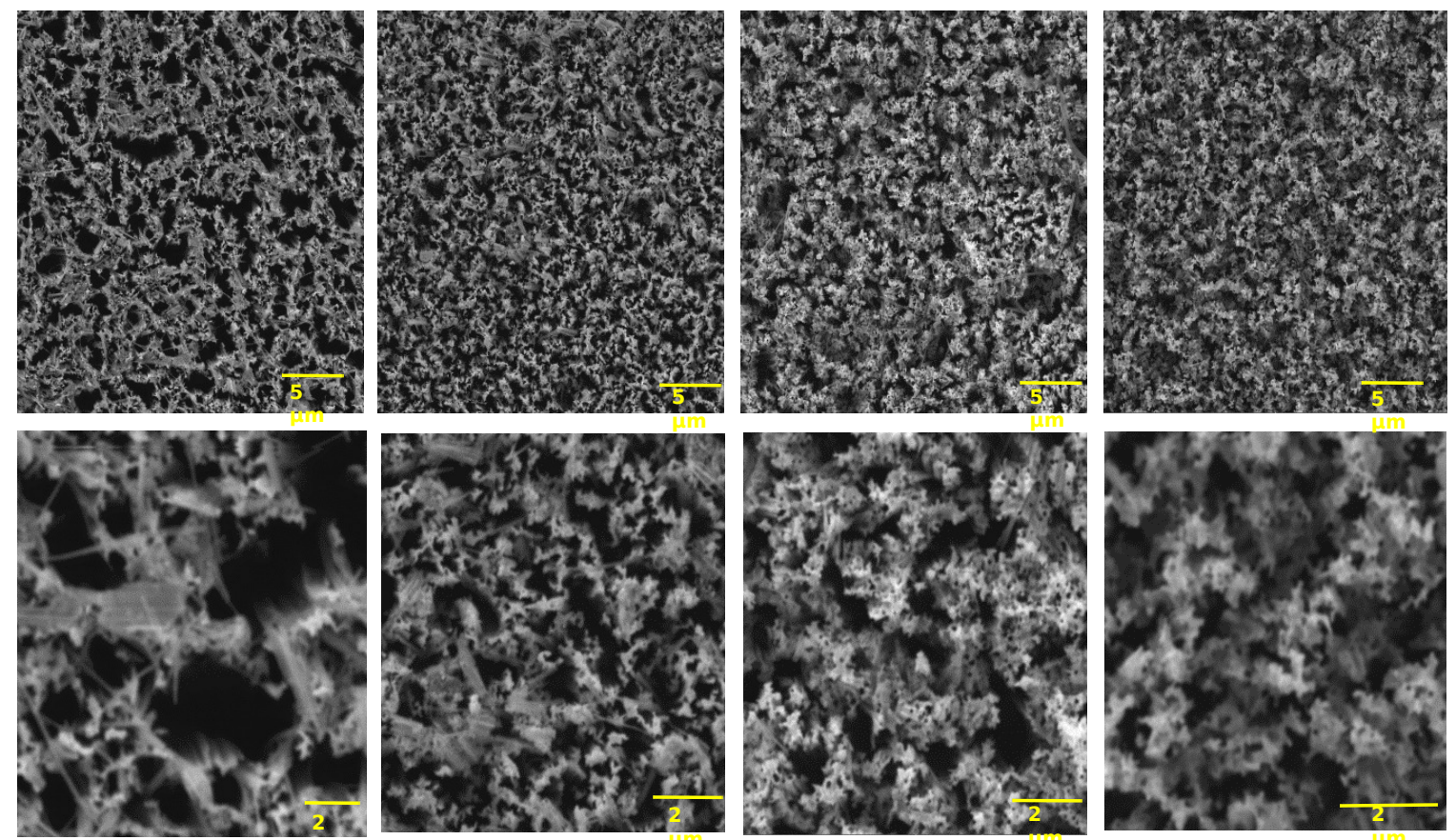

\section{Fig. 2: (a}

various ) concentration of ) molar ratio of ) $\mathrm{AgNO}_{3}$ $\left.\begin{array}{c}\text { of (cr } \\ \text { of }\end{array}\right) \underset{\mathrm{AgNO}_{3}}{\mathrm{AgNo}}$

(a) $0.008 \mathrm{M}$, (b) $0.004 \mathrm{M}$, (c ) $0.003 \mathrm{M} \&$ (d) $0.002 \mathrm{M}$ with different magnification (7kX \& $20 \mathrm{kX})$.
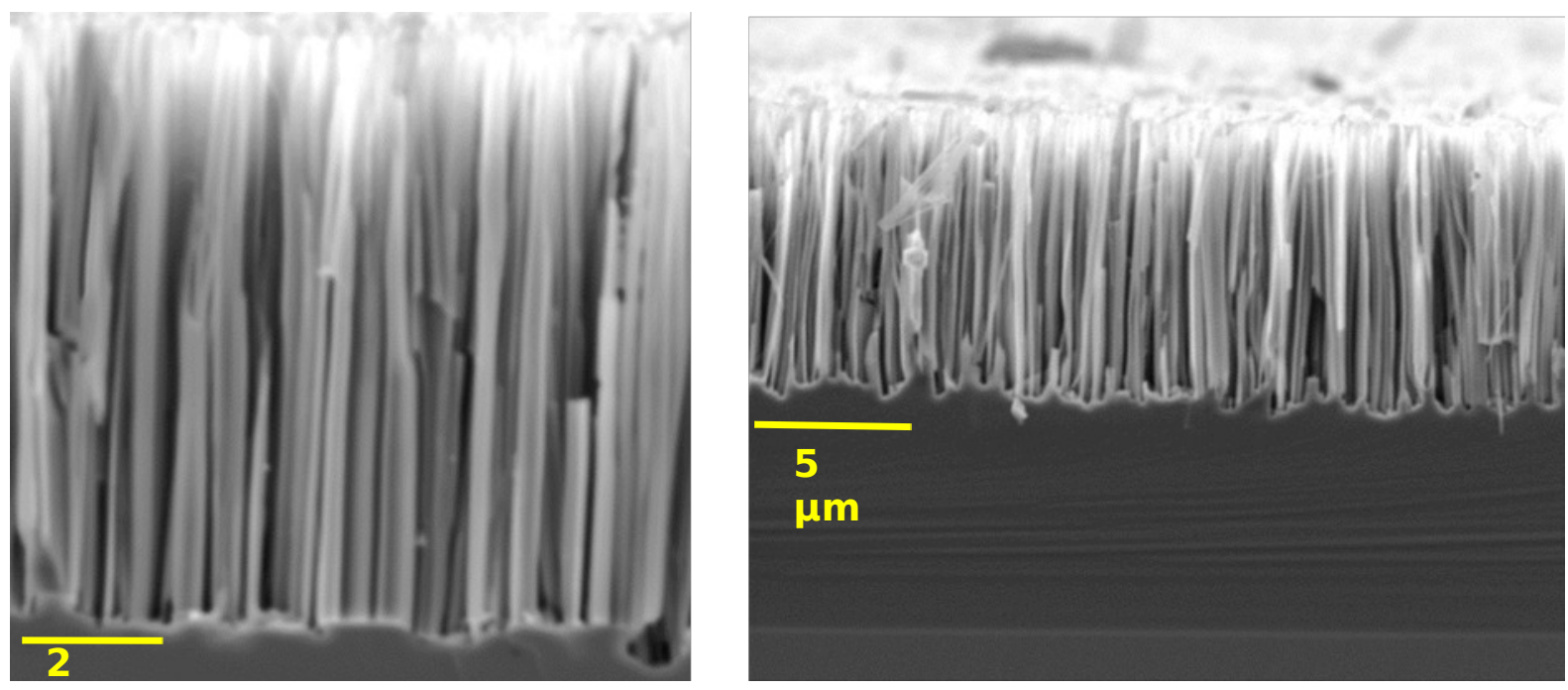

Fig. 3: Cross sectional SEM images of nanostructured Si for sample (b) 0.004M of $\mathrm{AgNO}_{3}$ with different magnification (7kX \& 20kX).

\subsection{UV- Visible Spectroscopy}

The optical properties of the prepared Si nanostructures were studied using surface reflectance. The results shown in Fig. 4 are reflectance spectra for nanostructured Si for various concentration of $\mathrm{AgNO}_{3}$ solution. The measured reflectance of the silicon nanostructures is from $30 \%$ in longer wavelengths $(800 \mathrm{~nm})$ and gradually decreases to below $10 \%$ at lower wavelengths $(300 \mathrm{~nm})$. The reflectance is low across the entire silicon absorption spectrum making it an especially viable candidate for an antireflection coating on silicon-based solar photovoltaic cells. The average surface reflectance of the Si substrate in 
the measured range decreased dramatically from $50 \%$ for the Si reference to less than $5 \%$ in the lower wave length region for sample (b) $\left(0.004 \mathrm{M}\right.$ of $\left.\mathrm{AgNO}_{3}\right)$ having silicon nanostructures on the surface. It is noted that larger nanostructures generally have a lower surface reflectance and that future work is needed to optimize the surface structures for both geometry and desnsity. Already, however, black silicon was produced.

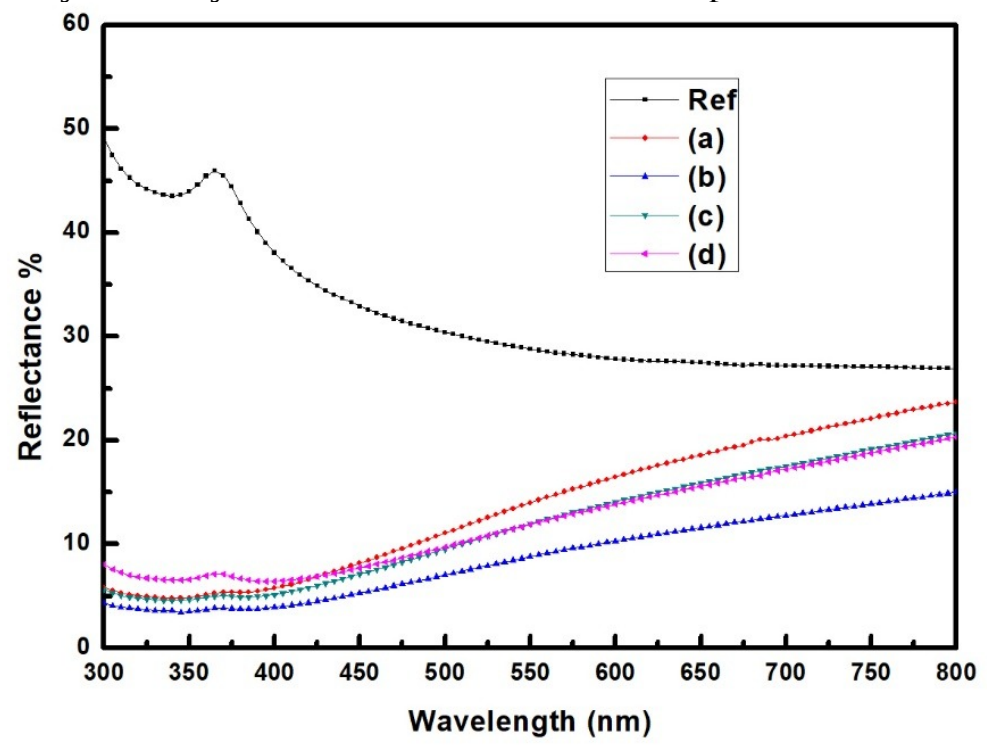

Fig. 4: UV-visible reflectance spectra of nanostructured $\mathrm{Si}$ for various concentrations of molar ratio of $\mathrm{AgNO}_{3}$ (a) $=0.008 \mathrm{M},(\mathrm{b})=0.004 \mathrm{M},(\mathrm{c})=0.003 \mathrm{M} \&(\mathrm{~d})=0.002 \mathrm{M}$

\subsection{Application to Solar Photovoltaic Technology}

This preliminary analysis, however, is promising when compared to other attempts [23] and when additional optimization could lead to a viable wet-chemical processing method of creating black silicon when coupled with atomic layer deposition (ALD) $[24,25]$. The preparation of low-cost black silicon is particularly promising in solar photovoltaic (PV) applications [26-29]. Often the best results of a black silicon approach use expensive techniques such as femtosecond lasers [30], which would be challenging to scale up for mass production. Scaling is extremely important for solar photovoltaic applications, as vast areas of PV are needed to provide terawatts of power [31] needed for a sustainable global energy supply [32]. Already black silicon PV with interdigitated back-contacts have achieved over $22 \%$ efficiency with ALD passivation of a more expensive method (cryogenic deep reactive ion etching) of fabricating silicon nanostructures [33]. Future work is needed to both optimize the concentration and potentially move to a multi-step etch following [23] and then include ALD passivation following [33] to make a mass-manufacturable high-efficiency black silicon based PV device.

\section{Conclusions:}

From the observed SEM results, the morphological properties of silicon nanostructures produced with MaCE with respect to changes in the catalyst concentration was investigated. The depth of the different silicon nanostructures was revealed by cross sectional SEM. The growth physics of silicon nanostructures were discussed based on the observed SEM results. The optical characterization results, indicated that MaCE is a promising as a form of producing black silicon where the reflectance dropped by an order of magnitude in the visible region. The results of this approach make MaCE a promising technically viable candidate for an antireflection coating system of black silicon solar photovoltaic cells. MaCE is a of simple, wet-chemical, and scalable approach to enhance the optical absorption of Si 
and improve the overall efficiency of the solar cell without adding significantly to the complexity, capital expenditure or cost of production.

\section{Disclosures:}

The authors declare no competing financial interests.

\section{Acknowledgement:}

The authors are thankful to the support from DST-SERB/F/1829/2012-2013, Fulbright Finland, and DST - PURSE programme MK University, for providing the SEM facility.

\section{References:}

[1] A.G. Cullis, L.T. Canham, P.D.J. Calcott, The structural and luminescence properties of porous silicon, J. Appl. Phys. 82 (1997) 909

[2] C.H. Foslia, A. Thøgersen, S. Karazhanov, E.S. Marstein, Plasmonics for Light Trapping in Silicon Solar Cells, Energy Procedia 10 (2011) 287 - 291

[3] Riccardo Rurali, Colloquium, Structural, electronic, and transport properties of silicon Nanowires, Rev. Mod. Phys. 82, 427 (2010)

[4] P. Steiner, W. Lang, Micromachining applications of porous silicon, Thin Solid Films 255 (1995) 52

[5] H.C. Shin, J. Corno, J.L. Gole, M.Liu, Porous silicon negative electrodes for rechargeable lithium batteries, J. Power Sources 139 (2005) 314

[6] V. Kumar, S. Saxena, V. Kaushik, K. Saxena, A. Shuklac, R. Kumar, RSC Adv. 4 (2014) 57799.

[7] J. Chen, C. Chen, C. Wong, C. Chen, Appl. Surf. Sci. 392 (2017) 498.

[8] L. Li, Y. Liu, X. Zhao, Z. Lin, C. Wong, Appl. Mater. Interfaces 6 (2014) 575.

[9] B. Huang, Y. Yang, H. Cheng, Nanotechnology 24 (2013) 475502.

[10] Besma Moumni, Abdelkader Ben Jaballah, Correlation between oxidant concentrations, morphological aspects and etching kinetics of silicon nanowires during silver-assist electroless etching. Applied Surface Science 425 (2017) 1-7

[11] K. Tsujino, M. Matsumura, Texturization of multicrystalline silicon wafers for solar cells by chemical treatment using metallic catalyst, Sol. Energy Mater. Sol.Cell. 90 (2006) 100.

[12] Role of catalyst concentration on metal assisted chemical etching of silicon, J. Cichoszewski M. Reuter F. Schwerdt J.H. Werner Electrochimica Acta, 109 (2013) 333- 339

[13] Z. Huang, N. Geyer, P. Werner, J. de Boor, U. Gösele, Metal-Assisted Chemical Etching of Silicon: A Review, Adv. Mater. 23 (2011) 285

[14] S. Yae, N. Nasua, K. Matsumoto, T. Hagihara, N. Fukumuro, H. Matsuda, Nucleation behavior in electroless displacement deposition of metals on silicon from hydrofluoric acid solutions, Electrochim. Acta 53 (2007) 35

[15] Kalimuthu Vijayarangamuthu, ShyamaRatha, One-step synthesis of Au-coated porous silicon as a surface enhanced Raman scattering substrate for biomolecule detection, Materials Letters, 204, (2017), 115-119

[16] X. Li and P. W. Bohn. Metal-assisted chemical etching in $\mathrm{HF} / \mathrm{H}_{2} \mathrm{O}_{2}$. Appl.Phys. Lett. 77 (2000) 2572

[17] H. Asoh, F. Arai, S. Ono, Effect of noble metal catalyst species on the morphology of macroporous silicon formed by metal-assisted chemical etching, Electrochim. Acta 54 (2009) 5142 
[18] C. Yang, Y.J. Zhao, L.M. Kang, D.D. Li, W.W. Zhang, L.C. Zhang High-strength silicon brass manufactured by selective laser melting Materials Letters 210 (2018) 169-172

[19] Vladislav Dřínek, Mariana Klementova, Radek Fajgar, Pavel Dytrych, Silicon nanowires grown on metal substrates via self-catalyst mechanism, Materials Letters 160, (2015), 109-112

[20] N. Geyer, B. Fuhrmann, Z. Huang , J. de Boor , H.S. Leipner , P. Werner, Model for the Mass Transport during Metal-Assisted Chemical Etching with Contiguous Metal Films as Catalysts. Phys. Chem. C 116 (2012) 13446

[21] J. von Behren, L. Tsybeskov, and P. M. Fauchet, Preparation and characterization of ultrathin porous silicon films, Applied Physics Letters, 66 (1995) 13, 1662-1664

[22] R. J. M. Fonseca, J. M. Saurel, A. Foucaran, J. Camassel, E. Massone, T. Taliercio, and Y. Boumaiza, Acoustic investigation of porous silicon layers, Journal of Materials Science, 30 (1995) 1, 35-39

[23] Hutagalung, S. D., Fadhali, M. M., Areshi, R. A., \& Tan, F. D. Optical and Electrical Characteristics of Silicon Nanowires Prepared by Electroless Etching, Nanoscale research letters, 12 (2017) 1 , 425.

[24] Jia, X., Zhou, C., \& Wang, W. Optimization of the Surface Structure on Black Silicon for Surface Passivation. Nanoscale Research Letters, 12 (2017) 1, 193.

[25] Branz, H. M., Yost, V. E., Ward, S., Jones, K. M., To, B., \& Stradins, P. Nanostructured black silicon and the optical reflectance of graded-density surfaces. Applied Physics Letters, 94 (2009) 23, 231121.

[26] Yoo, J. S., Parm, I. O., Gangopadhyay, U., Kim, K., Dhungel, S. K., Mangalaraj, D., \& Yi, J. Black silicon layer formation for application in solar cells. Solar energy materials and solar cells, 90 (2006) 18, 3085-3093.

[27] Koynov, S., Brandt, M. S., \& Stutzmann, M. Black nonreflecting silicon surfaces for solar cells. Applied Physics Letters, 88 (2006) 20, 203107.

[28] Yuan, H. C., Yost, V. E., Page, M. R., Stradins, P., Meier, D. L., \& Branz, H. M. Efficient black silicon solar cell with a density-graded nanoporous surface: optical properties, performance limitations, and design rules. Applied Physics Letters, 95 (2009) 12, 123501.

[29] Oh, J., Yuan, H. C., \& Branz, H. M. An 18.2\%-efficient black-silicon solar cell achieved through control of carrier recombination in nanostructures. Nature nanotechnology, 7 (2012) 11, 743-748.

[30] Sarnet, T., Halbwax, M., Torres, R., Delaporte, P., Sentis, M., Martinuzzi, S \& Bastide, S. Femtosecond laser for black silicon and photovoltaic cells. In Proc. SPIE 6881(2008) 688119

[31] Vesborg, P. C., \& Jaramillo, T. F. Addressing the terawatt challenge: scalability in the supply of chemical elements for renewable energy. Rsc Advances, 2 (2012) 21, 79337947.

[32] Pearce, J. M. Photovoltaics —a path to sustainable futures. Futures, 34 (2002) 7, 663674.

[33] Savin, H., Repo, P., Von Gastrow, G., Ortega, P., Calle, E., Garín, M., \& Alcubilla, R. Black silicon solar cells with interdigitated back-contacts achieve $22.1 \%$ efficiency. Nature nanotechnology, 10 (2015) 7, 624-628. 